Instructions for authors, subscriptions and further details:

http://rise.hipatiapress.com

\title{
Freire and Education
}

Ana Vidu ${ }^{1}$

1) Universidad de Barcelona, Spain

Date of publication: February 25th, 2016

Edition period: February 2016 - June 2016

To cite this article: Vidu, A. (2016) Freire and Education [Review of the Book]. International Journal of Sociology of Education, 5(1), 84-85. doi: 10.17583/rise.2015.1932

To link this article: $h t t p: / / d x . d o i . o r g / 10.17583 /$ rise.2016.1932

\section{PLEASE SCROLL DOWN FOR ARTICLE}

The terms and conditions of use are related to the Open Journal System and to Creative Commons Attribution License (CC-BY) 


\section{Reviews}

Darder, A. (2014). Freire and Education. New York, NY and London: Routledge.

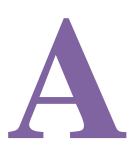

ntonia Darder, como académica, intelectual, y activista, reflexiona en su trabajo Freire and Education sobre las aportaciones a la pedagogía de la inmortal obra del autor brasileño. Darder analiza en profundidad la influyente aportación de Paulo Freire sobre la fuerza de la educación para democratizar la vida de los desposeídos. Si bien, su acercamiento a esta idea no se reduce a un análisis más o menos profundo sobre la filosofía del autor, sino que se introduce a ella misma en su propia reflexión al evidenciar cómo los pensamientos de Freire han iluminado su vida. Así, la autora se aproxima a la trayectoria de Freire de una manera innovadora, incorporando al análisis que realiza sobre el pedagogo sus propios relatos autobiográficos. Darder ejemplifica en su experiencia vital, como puertorriqueña en un entorno empobrecido y con escasos recursos educativos, las teorías de Freire acerca de la libertad a través de la justicia social y el relevante papel que la educación juega en ello.

En cuanto a las aportaciones fundamentales de esta revisión, sin duda amor y compromiso son dos de los conceptos que subyacen en la obra de Freire y, por ende, en el análisis que Darder hace de la misma. La autora recalca el acercamiento del educador a la situación de los oprimidos a través de ambos principios. El amor es una constante en la obra de Freire; debido a ello, tal y como recalca la autora de este trabajo, más allá del acercamiento cognitivo de Freire a la educación, se encuentra la idea del amor como central en el proceso de adquisición de conocimiento y en el acto de educar. Así, todo el desarrollo educativo tiene como núcleo el ser un suceso que parte del amor; siendo éste esencial para adquirir la solidaridad y participar en la lucha necesaria para transformar las ideologías y las prácticas opresivas de la educación pública.

En este sentido, otra de las contribuciones de este trabajo es, sin duda, el reflejo del apasionado compromiso con la liberación a través de la pedagogía 
de Freire. Esta idea aparece especialmente reseñada mediante la narración de las conversaciones que Darder mantuvo con él, siendo esta dialéctica otro de los recursos que la autora utiliza para profundizar en su filosofía. La posición de activistas en pro de la justicia social, tanto de Freire como de Darder, aparece continuamente reflejada en las ideas que desprenden sus conversaciones y el análisis de la autora.

Teniendo en cuenta estas dos aportaciones fundamentales, podemos afirmar que Antonia Darner logra reavivar la pedagogía del amor de Freire e imbuir al lector de su contribución a la transformación de las escuelas y de la sociedad. Así, esta lectura ofrece una mirada sincera e innovadora sobre la obra de Freire, tanto para los expertos en ella como para aquéllos y aquéllas que se acercan por primera vez al autor. Sin duda una relevante aportación para continuar reflexionando sobre el inspirador y revolucionario compromiso de Freire con la educación como elemento fundamental para la democratización social.

Ana Vidu, Universidad de Barcelona ana.vidu@ub.edu 